F.Barbariol $^{1 *}$, A.Benetazzo ${ }^{1}$, L.Bertotti ${ }^{1}$ L.Cavaleri $^{1}$, T.Durrant $^{2}$, P.McComb $^{2}$

This is an AAM - Author Accepted Manuscript of an article published in 2019 by Elsevier in Ocean Engineering available on ScienceDirect, https://doi.org/10.1016/j.oceaneng.2018.12.011

\title{
Large waves and drifting buoys in the Southern Ocean
}

1) Institute of Marine Science, ISMAR-CNR, Venice, Italy

2) Metocean group, Metservice, Raglan, New Zealand

*) corresponding author: francesco.barbariol@ve.ismar.cnr.it

\begin{abstract}
In February 2017, a buoy was deployed south of New Zealand at about $52^{\circ}$ South. In July the buoy broke its mooring and started drifting, still transmitting the essential information. During its short mooring period it also measured a particularly high wave. We present a detailed analysis of the storm, the measured and modelled spectra, allowing an analysis of the probability of the occurrence of single large waves. The availability of the data in both moored and drifting conditions allows the accuracy of the measurements in the two different situations to be quantitatively discussed.
\end{abstract}

\section{1 - Introduction}

In this paper we focus our attention on the Southern Ocean. Despite its large expanse, the importance role it plays in the global climate system, and the presence of very large storms, the Southern Ocean has received comparatively little attention. This was, at least in part, due to a lack of observations, with almost no observations of wind and waves available prior to the satellite era. Altimeter and scatterometers now provide invaluable data in the region, however, due to its remote location and harsh working environment, there still exists only a handful of deployed in-situ instruments.

In this paper, we focus on one such mooring, recently deployed at about $52^{\circ} \mathrm{S}$. More specifically we examine the case of a particularly large wave, measured soon after the buoy deployment. The discussion centers first on the storm itself, then on the conditions that characterise the region. This initial, relatively short dataset (14 months of data) has an almost unique characteristic that allows a kind of analysis rarely performed: part with the buoy 
moored, part with the buoy freely drifting. The analysis of the storm and the measured and modelled data leads also to discussion of how spectral conditions and possible maximum wave heights are related. In particular we aim at showing that single particularly large wave heights are not exceptional in the ocean, but rather it is the common practise of fixed-point measurements that gives them this appearance. From a different perspective, the comparative analysis of the moored-vs-drifting buoy data allows us to point out the respective implications of the data we then use.

Having framed the overall idea, in Section 2 we provide a description of the Southern Ocean and the recent efforts to collect data in the area. The specific event, its peculiarities and the data collected during the storm are described in Section 3. In 4 we show how moored and drifting buoys tend to provide different results, and we point out the reasons for this. In 5 we move to the extreme analysis discussing the various approaches and how they are supported by theory and evidence. This is followed by the overall conclusions and summary in Section 6.

\section{2 -The area of interest and the related data}

The ocean extent south of Australia and New Zealand is a very active area, with remarkable storms. The uninterrupted circular path around Antarctica leads to persistent strong winds. In turn this implies intense sea storms with high waves that radiate north as active swell (e.g., Alves, 2006). Rapizo et al. (2018) provide a good description of the general situation. These active wind and wave conditions bring with them enhanced air-sea exchanges and fluxes at the sea surface with all the derived implications for the local and also general climate (e.g., Hemer, 2010). Distances are huge, sea conditions are rough, permanent stations consequently expensive. For these reasons, the Southern Ocean is less studied than many other basins or oceans of the world. The Southern Ocean Flux Station (SOFS) buoy was the first semipermanent deep sea mooring in the Southern Ocean, moored on 4,500 m depth about $500 \mathrm{~km}$ south-west of Tasmania. It measures both atmospheric and sea parameters (down to $500 \mathrm{~m}$ depth; Schulz et al., 2012). Rapizo et al., 2015 report about the first three winter campaigns that lasted respectively 10,8 and 6 months. They provide a good description of the local wave climate, characterized by mainly unimodal systems from South-West, hence radiating from the more southern Antarctic storm belt. Although, according to local wind speed and peak frequency, these systems can mostly be classified as swell, being for the most part just out of the generation area, their spectra still retain most of the characteristics (spectral shape 
and average steepness) of a wind sea. In between 10 and $20 \%$ of the cases a bimodal situation, e.g., with also a wind sea from North-West, is present. Large wave heights were recorded, up to $13.14 \mathrm{~m}$ significant wave height $\left(H_{S}\right)$. A larger value was also reported by a second wave recorder on the buoy, but there are doubts about its quantitative reliability (?? personal communication?).

In February 2017 MetOcean Solutions Ltd moored a Triaxys directional wave buoy $10 \mathrm{~km}$ south-west of Campbell Island, about $600 \mathrm{~km}$ south of New Zealand (Figure 1). The buoy coordinates were (soon to be explained why) latitude $52^{\circ} 45.71^{\prime} \mathrm{S}$, longitude $169^{\circ}$ 02.54 ' E. Local depth is $147 \mathrm{~m}$. On May 19, shortly after its deployment and at the very beginning of the local winter season, the buoy measured $11.7 \mathrm{~m}\left(H_{s}\right)$ and a $19.4 \mathrm{~m}$ single wave height. Although this very large wave cannot be classified as a freak event (according to common definition, Draper, 1965), in this paper we analyse the storm that produced the wave and we make a detailed statistical analysis, focused on extreme heights, of both the related buoy and model data. On July 27, 2017, probably due to fatigue induced by the persistent rough sea conditions, the buoy broke its mooring and started drifting East (Figure 1). It could not be recovered but kept on transmitting the data, so that we can complement our study with a 14-month record of 3 hourly directional wave spectra (with their peak and integral parameters; 20-minute acquisitions) and maximum crest-to-trough wave heights, from February 06, 2017 to March 28, 2018. 


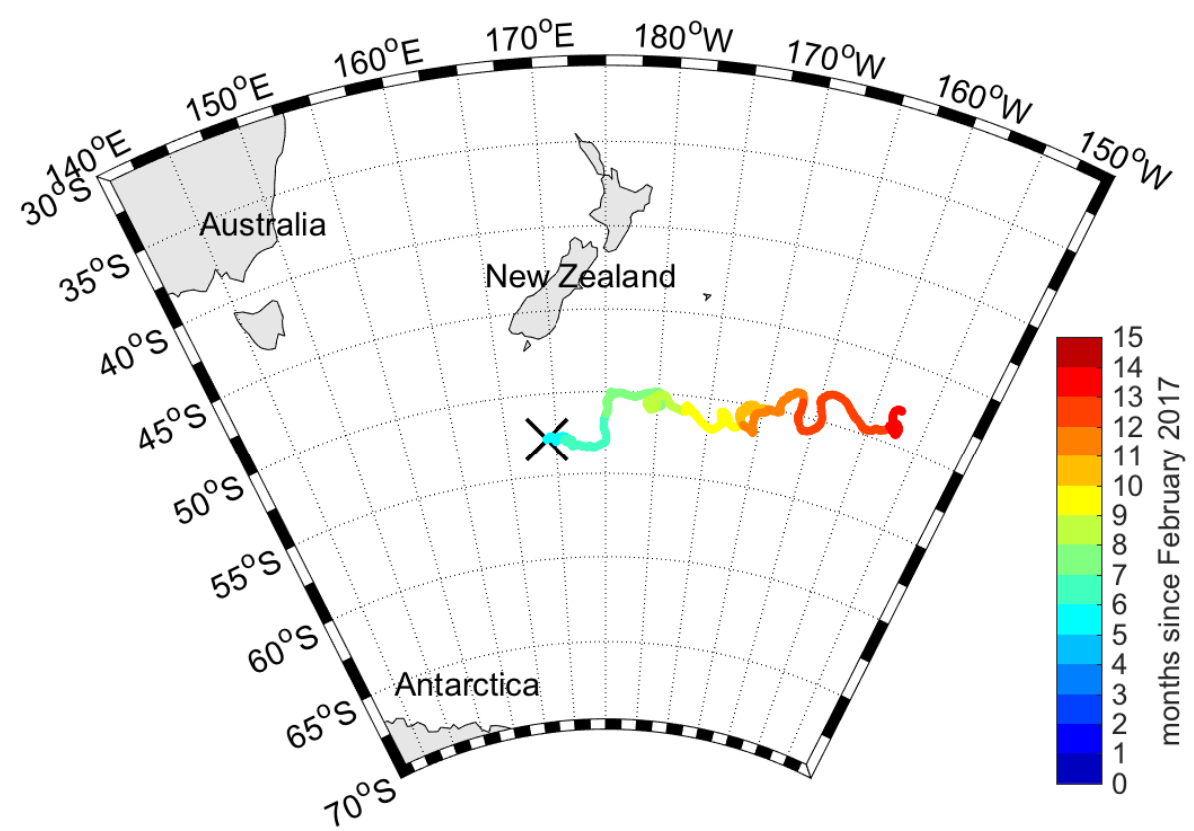

Figure 1 - Triaxis directional buoy mooring and drifting locations. The deployment was in the Southern Ocean at $52^{\circ} 45.71^{\prime} \mathrm{S}, 169^{\circ} 02.54^{\prime}$ E (black cross), south-west of Campbell Island, south of New Zealand. The buoy was moored until July 27, 2017. Since then, it operated as a drifting buoy.

\section{3 - Storm and data}

\section{1 - The storm}

Figure 2 and Figure 3 provide the sequential evolution of the storm we are studying (19-20 May) at six-hour interval $(03,09,15,21,03,09$ UTC) for wind and waves respectively. These data correspond to the, twice a day, 1 to 12 hour forecast fields of the European Centre for Medium-Range Weather Forecasts (ECMWF, Reading, U.K.). The Tco1279 meteorological model has $9 \mathrm{~km}$ resolution; the WAM wave model (Komen et al., 1994) runs on a grid with $14 \mathrm{~km}$ resolution. Details are available at http://www.ecmwf.int/en/forecasts/charts/obstat/?facets=Parameter,Wave\%20Height._The spectra are specified for 36 frequencies and 36 directions. Analyses are available at six-hour interval. We use short-term forecasts to have available hourly fields. Panels d of Figure 2 and Figure 3 show, respectively, the wind and wave fields at the local peak of the storm (21 UTC 19 May 2017).

In both Figure 2 and Figure 3, panel $a$ shows the conditions at 03 UTC on May 19 (henceforth 19/03). There are the cited frequent steep waves from South-West (henceforth, 
because of their frequent use, S-W, as the other cardinal directions $\mathrm{N}, \mathrm{E}$ ). As pointed out in the previous section, these waves have been recently generated and their spectrum, soon to be discussed, still retains characteristics, e.g. steepness, of a wind sea. At 09 UTC (panels b) the situation changes substantially. A cold front from $\mathrm{S}$ is rapidly moving $\mathrm{N}$ (as a preference, henceforth we use flow directions). Wind speed is up to $22 \mathrm{~ms}^{-1}$. A substantial wave system follows accordingly with $11 \mathrm{~m}$ (model) overall significant wave height $H_{s}$. At the buoy the most severe conditions are between 15 and 18 UTC (3c, 4c for wind and wave respectively). At this time, as we will soon discuss, both the wave systems, the NE moving "swell" and the $\mathrm{N}$ going wind sea, are present with about $45^{\circ}$ between their two directions. After this time both the systems abate, the NE one more rapidly, and the $\mathrm{N}$ one more slowly with only the latter system present after one day. Panels $3 \mathrm{~d}$ to $\mathrm{f}, 4 \mathrm{~d}$ to $\mathrm{f}$ show the progressive decay. 

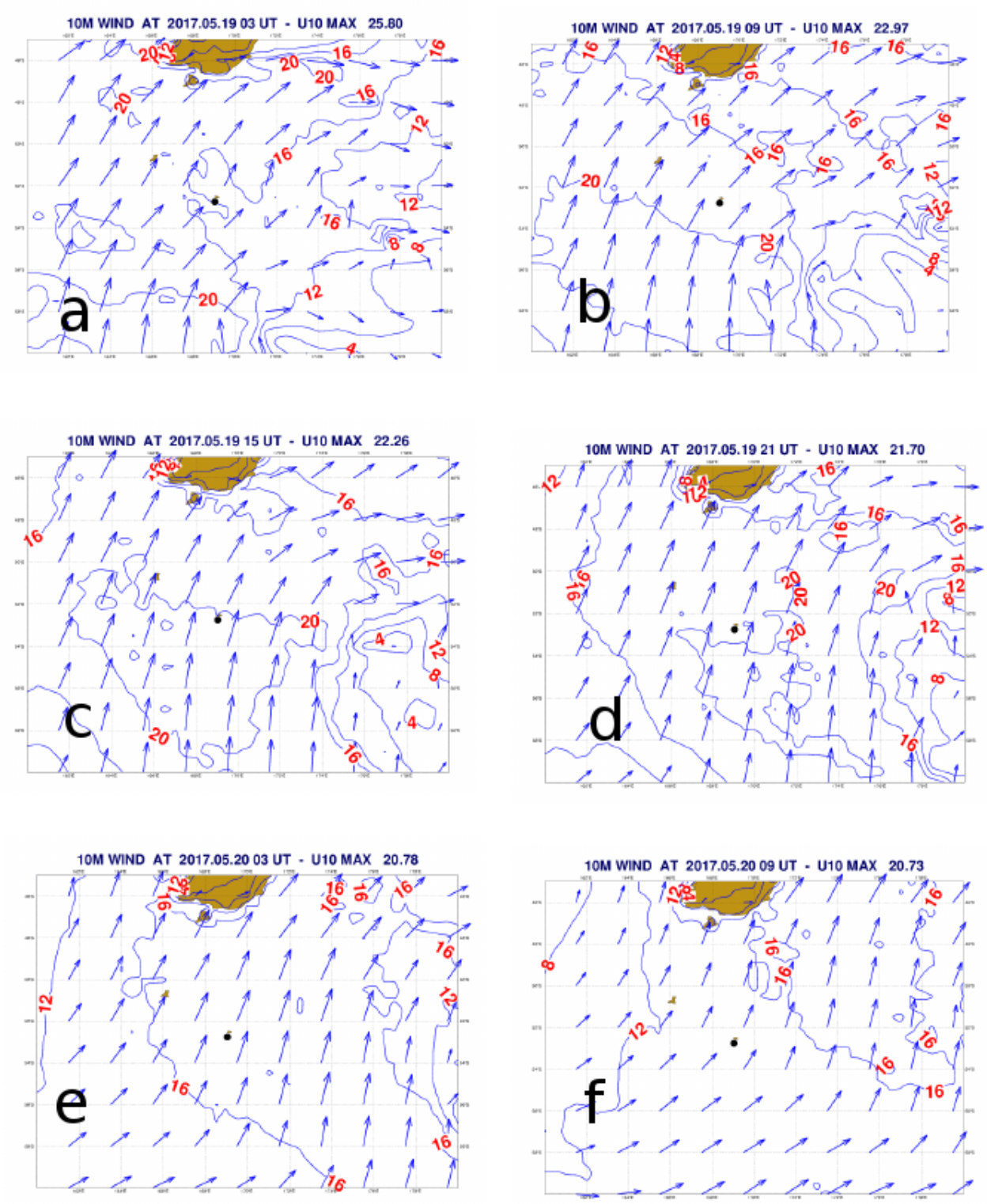

Figure 2 - Wind fields in the Southern Ocean at 03, 09, 15, 21, 03, 09 UTC 19-20 May 2017. Isotachs of $10-\mathrm{m}$ wind speed are at $4 \mathrm{~ms}^{-1}$ interval. The corresponding arrows are at 2-degree interval. The black dot shows the original position of the buoy when moored. 

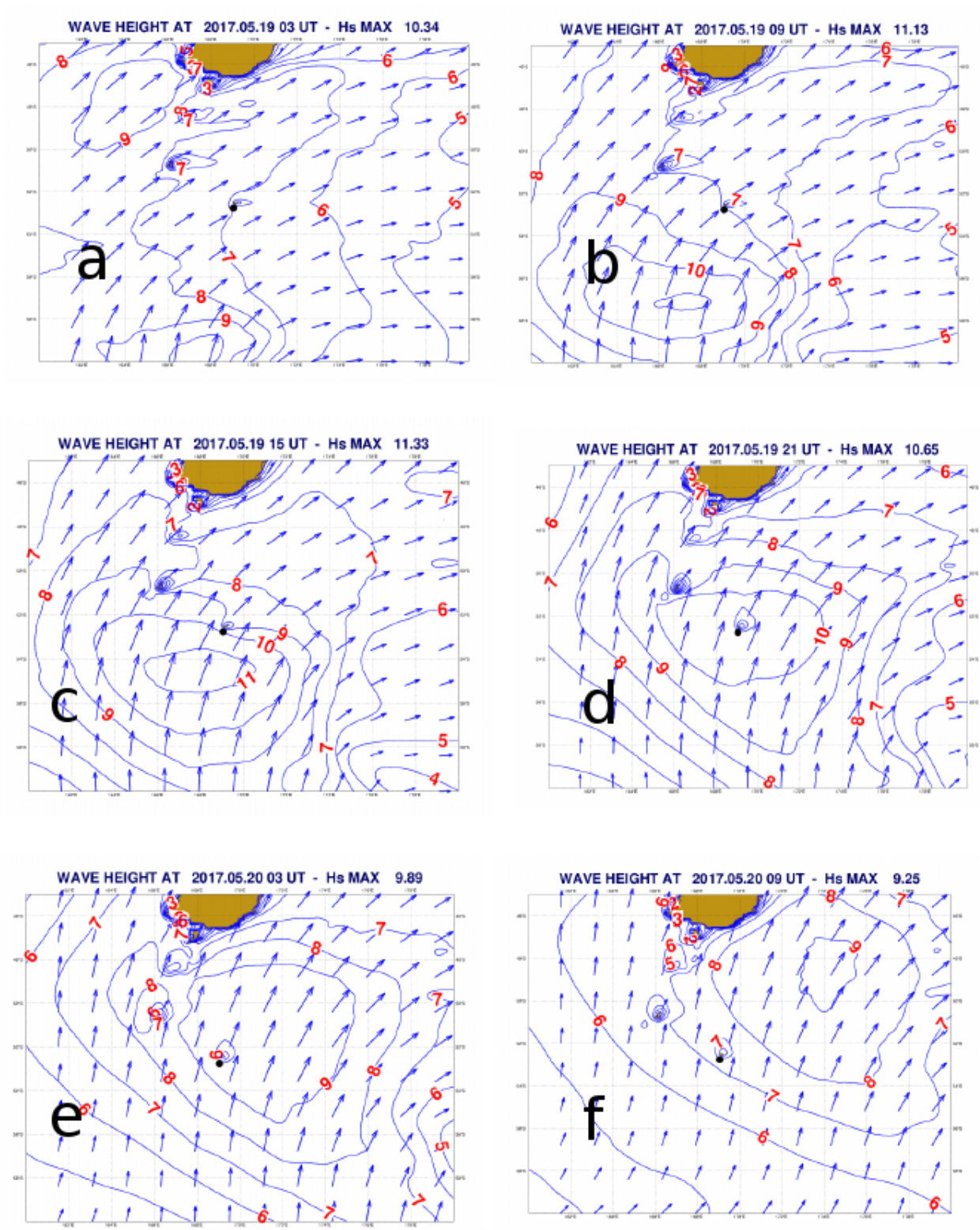

Figure 3 - Wave fields in the Southern Ocean at 03, 09, 15, 21, 03, 09 UTC 19-20 May 2017. Isolines of significant wave height are at $1 \mathrm{~m}$ interval. The corresponding arrows are at 2degree interval. The black dot shows the original position of the buoy when moored.

Before going into the detailed analysis of the model and buoy data, we point out a special characteristic of the storm. From the meteorological maps it is straightforward to derive that the cold front was moving about $500 \mathrm{~km}$ every 12 hours, i.e. at $\sim 40 \mathrm{kmh}^{-1}$. This $\left(11 \mathrm{~ms}^{-1}\right)$ is the group velocity of $14 \mathrm{~s}$ waves, which is the peak period of the $\mathrm{N}$ going wave system. This suggests it was a case of dynamical generation, which justifies the particularly severe sea conditions, and their rapid growth and slower decay at the buoy position. We are 
interested in investigating the possibility that the occurrence of this large wave height can be related to the characteristics of the sea state that produced it.

\section{2 - Buoy and model data}

Figure 4 shows the $H_{s}$, mean period $\left(T_{m}\right)$, mean direction $\left(\theta_{m}\right)$ together with directional spreading $\left(\sigma_{s}\right)$ and steepness $(\mu)$ at the buoy location according to measured and model data ( $\mu$ is defined as $\sigma k_{m}$, with $\sigma$ the variance and $k_{m}$ the mean wave number, this accounting also for the spectral bandwidth according to Fedele \& Tayfun, (2009). There is an underestimate by the model during the first part of the storm, in particular an $H_{S}$ of $10.8 \mathrm{~m}$ (model) vs $11.7 \mathrm{~m}$ (buoy) at peak time, $10.33 \mathrm{~m}$ vs $11.03 \mathrm{~m}$ at the time of the $19.4 \mathrm{~m}$ measured maximum wave height. Note that the buoy results are available at 3-hour interval, while hourly data are shown for the model. Given the underestimate by the model before the time of the event (identified by the yellow vertical line), there is also an underestimate of the mean spectral wave period $T_{m}$ (corresponding to the average zero-crossing wave period). Both for $H_{s}$ and $T_{m}$ the buoy-model fit is much better after 19/21. Wave steepness is maximum at the peak of the storm, with values typical of a wind sea ( $\mu \sim 0.05-0.06)$, showing similar evolution for buoy and model estimates. On the contrary at the peak time we find a larger difference in direction, the model apparently indicating a higher percentage of waves moving to the NE. Nevertheless, besides a buoy-model directional bias that during the storm ranges between $10^{\circ}$ and $45^{\circ}$ degrees (relative to peak directions), the evolution of the other wave characteristics provided by the model is in agreement with the buoy data. At the same time, the model, with its meteorological and wave components, provides (i) a synoptic view that helps to interpret the buoy observations, and (ii) 2D directional wave spectra at the buoy location that we can use to complement the information from the buoy. 

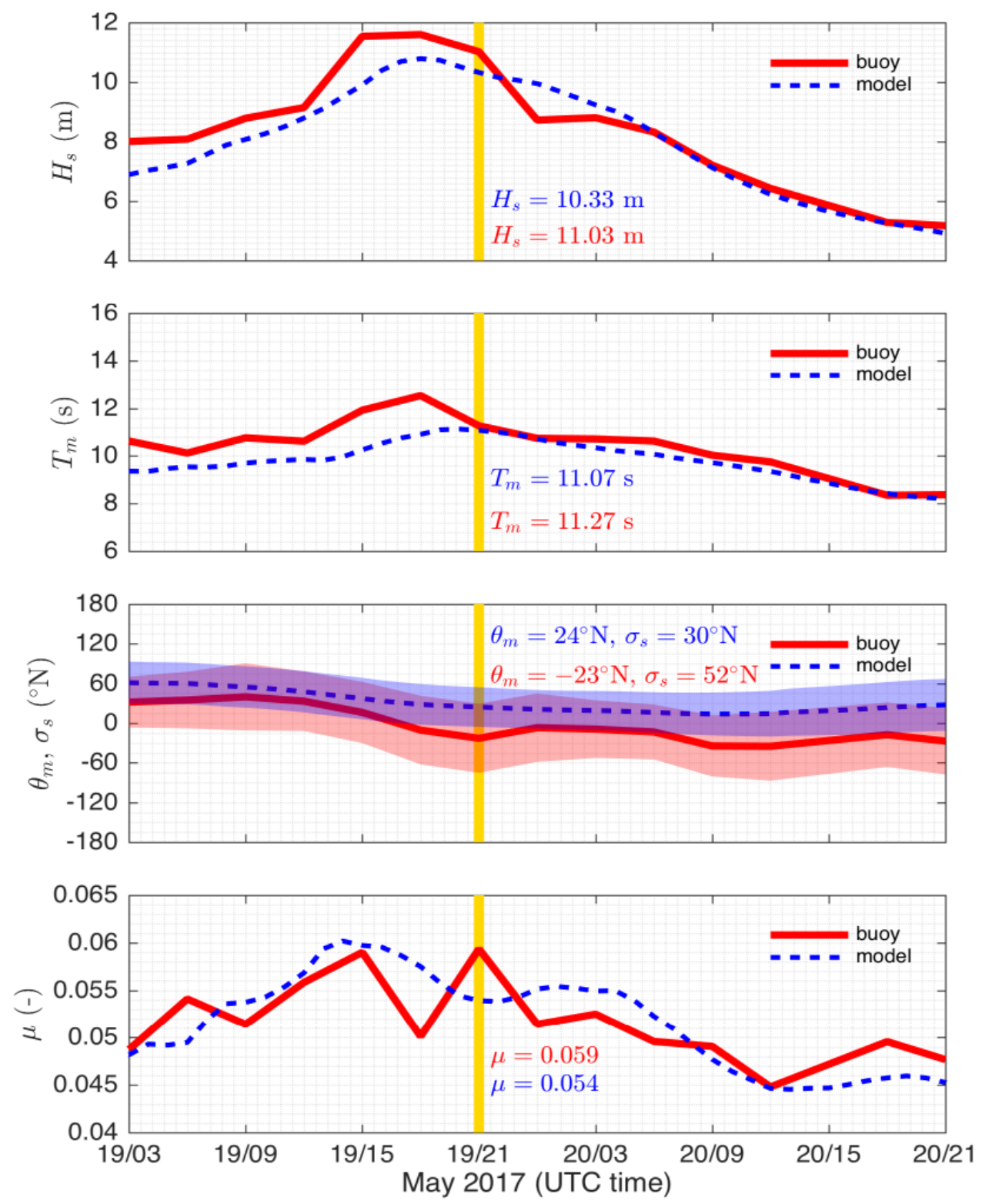

Figure 4 - Time series of spectral wave parameters from the buoy (red) and the model (dashed, blue), during the storm that produced the highest wave height $(19.4 \mathrm{~m})$ recorded by the buoy. $H_{s}$ is spectral significant wave height, $T_{m}$ is mean spectral wave period, $\theta_{m}$ is mean wave direction, $\sigma_{s}$ is directional spreading, $\mu$ is an integral measure of mean wave steepness. The yellow line indicates the time the $19.4 \mathrm{~m}$ wave height occurred, with spectral parameter values at that time reported.

Figure 5 and Figure 6, panels $a$ to $f$, show the 2D spectra from both the buoy and the model respectively. The same times of Figures 2 and 3 are used. Looking at the, albeit slightly underestimated, model 2D spectra (Figure 6), we have a clear idea of the evolution of the wave conditions at the buoy. At 19/03 there is only the previous wave system from SW, 
with the mean direction shifting more toward $S$ to $N$ moving to higher frequencies. At 19/09 a first hint of new energy from $180^{\circ}$ appears. Quickly growing (remember the cited dynamical generation), this new system becomes rather substantial at $19 / 15$, but with still lower energy compared to the pre-existing system from $\mathrm{S}-\mathrm{W}$. The $\mathrm{N}$ going system is fully developed at 19/21 with a peak frequency similar to, but lower energy than, the NE one. The two different energy peaks are clearly visible in the 16 and 17 UTC 2D spectra (not shown to keep a regular time interval). We point out that, except for this detail, there is not much more information in the not-shown single hourly spectra. At 20/03 the bulk of energy has moved toward $180^{\circ}$ (incoming direction). This is more and more the case with time passing, as seen at 20/03 and 20/09 where, beside the $\mathrm{N}$ going now swell, there is only a slight hint of the previous one from SW.

Several things need to be specified. In contrast to the cited oceanographic convention we generally use, the spectra have been plotted as incoming direction to have them at the centre of each panel. Oceanographically they would have been split between the upper $\left(360^{\circ}\right)$ and lower $\left(0^{\circ}\right)$ borders. For their shape, the limited directional information, derived from the $a_{1}, b_{1}, a_{2}, b_{2}$ frequency dependent coefficients (see Longuet-Higgins et al., 1963), it is evident in the buoy spectra where the analysis procedure tends to recognize only one main direction and to spread the energy over almost $360^{\circ}$. This is well quantified by the buoy directional spreading that is much larger than the model one during the whole storm (Figure $4,52^{\circ}$ instead of $30^{\circ}$ at 19/21). On the contrary the model clearly recognizes, as expected, the two different wave systems and, taking into account the angle between the two wave systems, keeps the energy in the semi-circle around the mean direction. This is evident in Figure 7 where we plot the evolution throughout the storm of the overall energy directional distributions for the buoy and the model (upper and lower panels, respectively). The progressive shift in relative energy, hence in mean direction, is well represented in the overall energy distributions of Figure 7. Here we see even better the narrower model distributions and the progressive shift of the mean and dominant directions. We stress this point because of its importance in the following extreme analysis. 

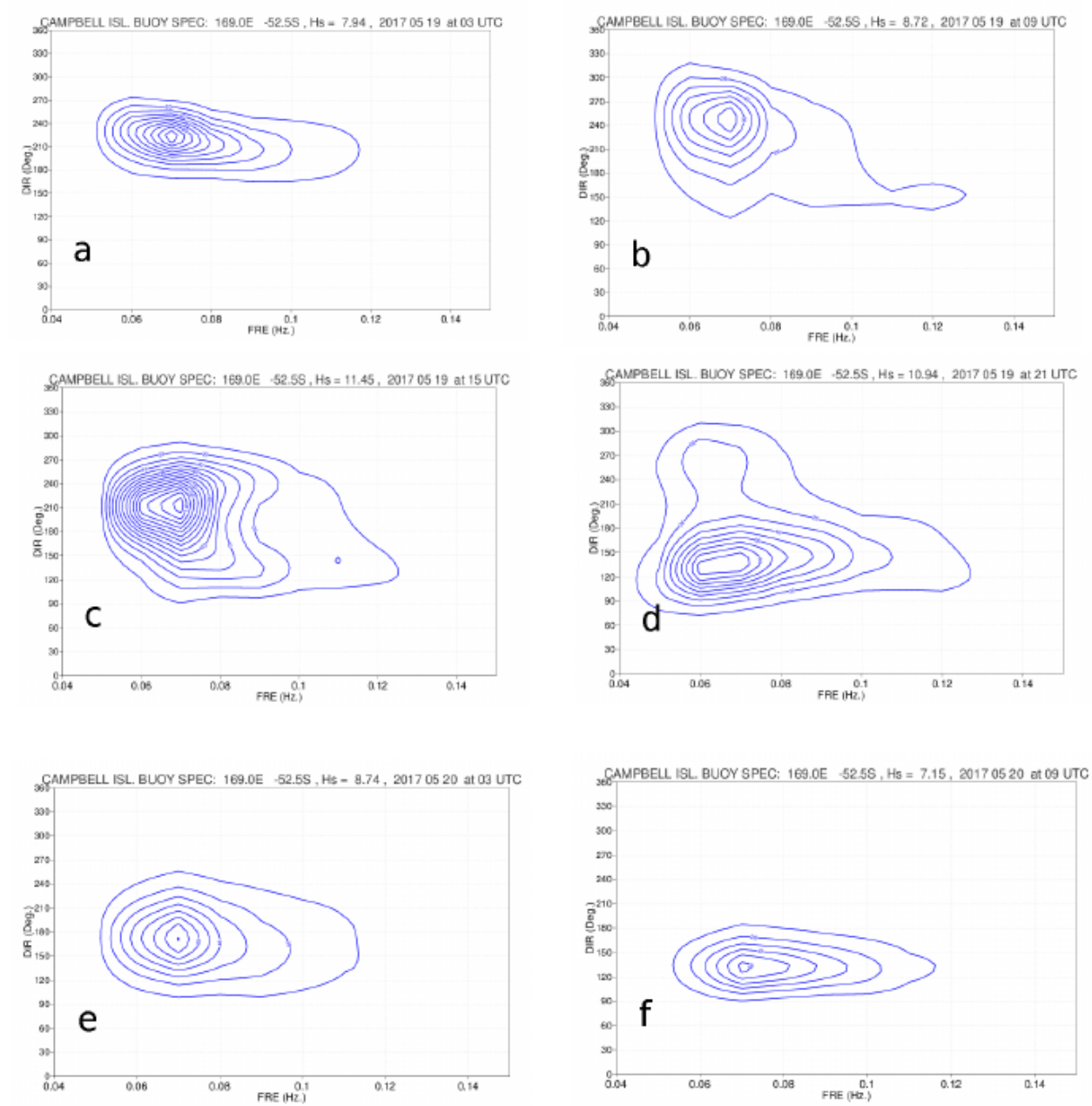

Figure 5 -Two-dimensional wave spectra from the Tryaxys buoy at 03, 09, 15, 21, 03, 09 1920 May 2017. Energy density isolines at $20 \mathrm{~m}^{2} \mathrm{~s} \mathrm{rad}^{-1}$ interval. 

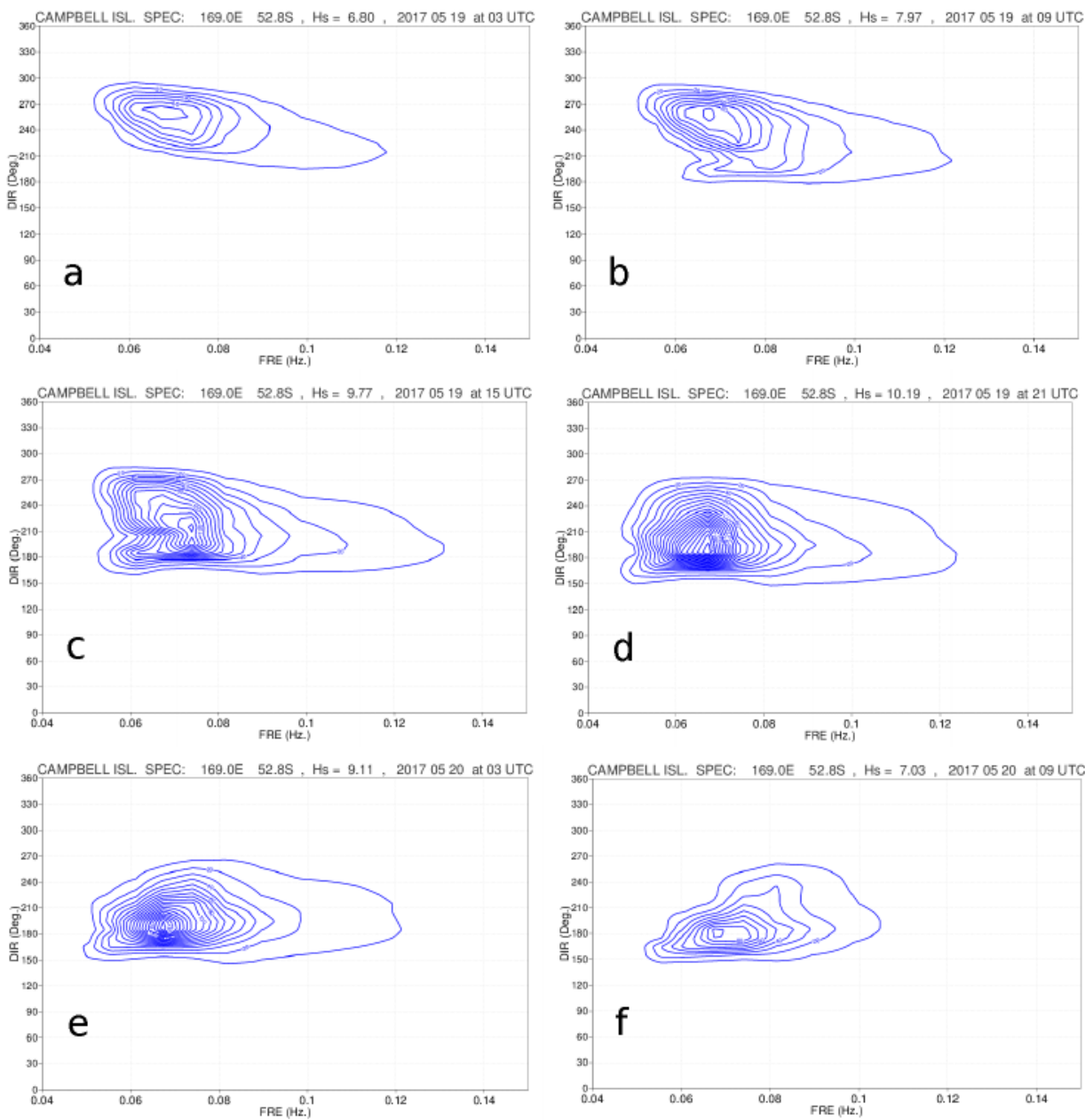

Figure 6 - As Figure 5, but for model spectra. 


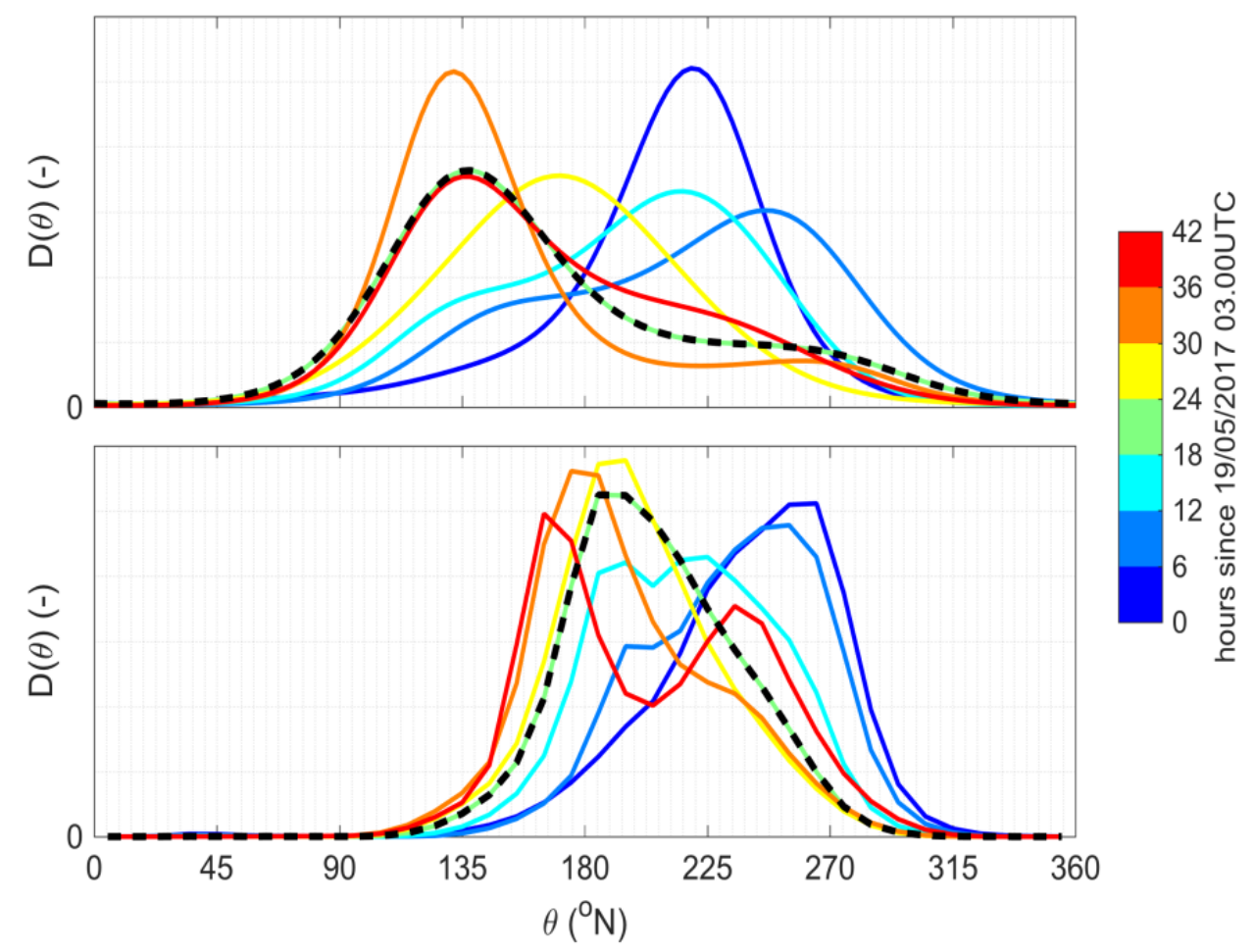

Figure 7 - Evolution of the overall directional energy distribution $\mathrm{D}(\theta)$ for the buoy and model spectra (upper and lower panels, respectively). The directional distributions are plotted at 6-hour interval. The 19/21 distribution is indicated by dashed black line.

The overall spectral information provides the background for the extreme wave analysis. However, to also offer a feeling of the ground on which we operate, it is first worthwhile to make a general, although statistical, comparison between the data the buoy has collected when in moored and drifting conditions.

\section{4 - Moored and drifting conditions}

We take advantage of the uniqueness of the present dataset of being collected first in mooring, then in drifting conditions (henceforth $\mathrm{M}$ and $\mathrm{D}$, respectively). This allows a keen comparison between the characteristics of the wave data obtained in these two conditions. Implicitly this is a critical analysis of the buoy data we all use.

The first obvious comment is that the main difference between $\mathrm{M}$ and $\mathrm{D}$ is to provide respectively absolute ( $\mathrm{M}$, at a fixed point in space) and relative (to the oceanic current, D) measurements. Currents may have any distribution, but in a storm there is always a strong component associated with the local wind and wave conditions. This implies that the $\mathrm{M}$ wave 
periods are shorter than the $\mathrm{D}$ ones because during a wave period the $\mathrm{D}$ buoy has drifted ahead, and it takes therefore longer for it to record the passage of the next wave.

\begin{tabular}{|c|c|c|c|c|c|}
\hline \multicolumn{2}{|c|}{} & moored & drifting & drifting-moored & relative difference \\
\hline \multirow{2}{*}{ buoy } & $H_{\text {max }} / H_{s}$ & 1.50 & 1.53 & 0.03 & $2 \%$ \\
\cline { 2 - 6 } & $H_{s} / L_{m}$ & 0.039 & 0.036 & -0.003 & $-8 \%$ \\
\hline model & $H_{s} / L_{m}$ & 0.038 & 0.036 & -0.002 & $-5 \%$ \\
\hline
\end{tabular}

Table 1 - Mean value of the indicated parameters for moored and drifting conditions. $L_{m}$ is the mean wavelength (related to $T_{m}$ via the linear dispersion relationship).

The overall statistical comparison is summarized in Table 1 where, beside the $H_{\max }$ values we will soon comment about, we report the mean (ensemble average) value of the measured wave steepness in moored and drifting conditions. This has been calculated as $H_{s} / L_{m}$, with $L_{m}=(g / 2 \pi) T_{m}^{2}$ the wavelength on the base of the mean period $T_{m}$ and the linear dispersion relationship ( $g$ is gravity acceleration). We find a markedly lower steepness for D data. Small in itself, -0.003 , still this is an $8 \%$ difference. This is quite substantial as it would imply that at, e.g., each $100 \mathrm{~m}(8 \mathrm{sec})$ wave the buoy would move ahead of about $8 \mathrm{~m}$. On the other hand part of this difference may depend on different meteo-oceanographic conditions. We have explored this possibility by repeating the statistics using the ECMWF wave model data (at times and locations of the buoy). This result too is shown (last row) in Table 1, and indeed we see that part of the buoy D-M difference appears justified by the different wave conditions. However, there still remains a -0.001 ( $3 \%$ in relative terms) difference (further digits are available, but not significant) that we associate with better confidence to the drifting of the buoy. In quantitative terms, with the above example we derive close to $3 \mathrm{~m}$ buoy shift at each wave cycle, hence an average drift of $0.37 \mathrm{~ms}^{-1}$. This is the order of magnitude we expect and we have somehow verified checking the distance run by the buoy in the eight-month drift we have analysed. Direct counting with the sequential buoy geographical coordinates leads to an overall distance of $6490 \mathrm{~km}$. Distributed uniformly on the 216 days analysed period, this suggests an average drift of $0.35 \mathrm{~ms}^{-1}$. Granted the occasional close fit with the above derived slope figure $\left(0.37 \mathrm{~ms}^{-1}\right)$, this is a strong support to the offered conclusion of a different steepness recorded by mooring and drifting buoys.

In principle the $\mathrm{M}$ and $\mathrm{D}$ conditions should not differ for what concerns $H_{s}$ and $H_{\max }$. However, mooring has a mechanical action on the buoy, more or less tensioned depending on the wave conditions and the depth (a lower depth implies shorter, hence less 'giving', lines). 
This leads to the well-known, or at least often discussed, tendency of moored buoys to go around (avoiding) the higher crests. It is intuitive that this is more manifest the steeper the wave and the shorter the crest (in the transversal direction). Therefore we expect a more manifest effect on the value of the highest wave $H_{\max }$. The results in Table 1 are clear in this respect. The mean ratio $H_{\max } / H_{s}$ is $2 \%$ higher for $\mathrm{D}$. Note that this does not ensure the buoy measures the correct $H_{S}$, but the relative conditions between $\mathrm{M}$ and $\mathrm{D}$ for the reported $H_{\text {max }}$ values are clear. We add that this difference, 1.53 instead of 1.50 , is a robust result as we have verified repeating the statistics for various subsamples of the data.

There is another effect worthwhile to mention that concerns the surface profile derived from raw buoy data. In steep conditions, and certainly so for a breaking wave, a buoy will have a tendency to move with the crest, i.e. "to remain" on it longer than expected from its ideal orbital motion. In the resulting record, and obviously with the same wave height, this tends to lower the recorded front steepness (same vertical motion in a longer time) and to round the crest longitudinal (direction of motion) profile. The consequences are felt more strongly in $\mathrm{M}$ because, soon after the crest has passed, the mooring line forces a hasty return, in so doing (same vertical motion in a shorter time) artificially steepening the back side of the recorded wave.

\section{5 - Extreme analysis, or how large can the largest wave be in a record}

In this section we analyse the $19.4 \mathrm{~m}$ wave from the point of view of a measuring buoy, followed by the broader view of a $2 \mathrm{D}$ analysis.

The obvious and first question is: given the described storm, how unexpected could a $19.4 \mathrm{~m}$ high wave be? Granted this is not an everyday event, we must not forget that we are focusing on this event a posteriori. Therefore its statistical significance should be considered not as a general event, but with respect to the local conditions at that moment. The remarkable fact is that such an event was recorded by a single-point instrument. Therefore we will focus first on the single-point approach followed by a brief, but sufficient, excursus on a $2 \mathrm{D}$ view of the matter.

The largest single wave height in a sea state or in a time record at a specific position is of course of practical interest. The guidelines for marine structure designers (DNV GL, 2017) recommend the use of the linear extreme model from Naess (1985), which states that the expected maximum crest-to-trough $\bar{H}_{\text {max }}$ is given by 


$$
\bar{H}_{\text {max }}=2 \sigma \sqrt{1-\psi}(\ln N)^{1 / 2}\left(1+\frac{\gamma}{2 \ln N}\right)
$$

where $\sigma=H_{S} / 4$ is the standard deviation of the sea surface, $\psi$ is the first absolute minimum of the temporal autocovariance function, $N=D / T_{m}$ is the average number of waves with $D$ the considered duration and $T_{m}$ the mean period, $\gamma \approx 0.5772$ the Euler-Mascheroni constant. Physically, as it is expected, the higher the waves (hence $\sigma$ ) and the lower the autocovariance (i.e. the higher the correlation between sequential waves) and the larger the number of waves, the higher the probability of single large waves. Casas-Prat \& Holthuijsen (2010) found that the Naess linear model fits well the statistics derived from buoy data. The possible effects of non-linearity are briefly discussed in the next and final section.

Figure 8 shows, according to buoy (left panels) and model data (right panels), how the $H_{S}$ evolved over 19-20 May 2017, the corresponding $\bar{H}_{\text {max }}$ estimate and the actual buoy data, plus the $\bar{H}_{\max }$ confidence limits (one standard deviation covering $72 \%$ of the $H_{\max }$ distribution). Not surprising, the 19.4 event lies outside of this interval. From this point of view, it is, on the contrary, rather surprising that only one of the 13 remaining events appears out of the confidence limits.

The variability of $\bar{H}_{\text {max }}$ versus $H_{s}$ is better represented normalizing, at each record, $\bar{H}_{\text {max }}$ versus the corresponding $H_{s}$. The result is shown in panels c, d. The question is now if 19.4 was a random event or conditions were particularly favourable to a large wave. In panels e, f of Figure 8 , beside $\bar{H}_{\text {max }} / H_{s}$, we plot also the first minimum of the autocovariance $\psi$ and the number of waves in each record (all normalised with respect to their 19/21 value). Granted a certain level of variability in the buoy data, these parameters do not suggest particularly favourable conditions to the appearance of large waves. Therefore the 19.4 event appears as a statistically large wave (7\% extreme Naess probability with buoy spectrum, $4 \%$ with model spectrum) happened during high wave conditions. Note that, however severe, the considered storm was not the heaviest one during the record period. 

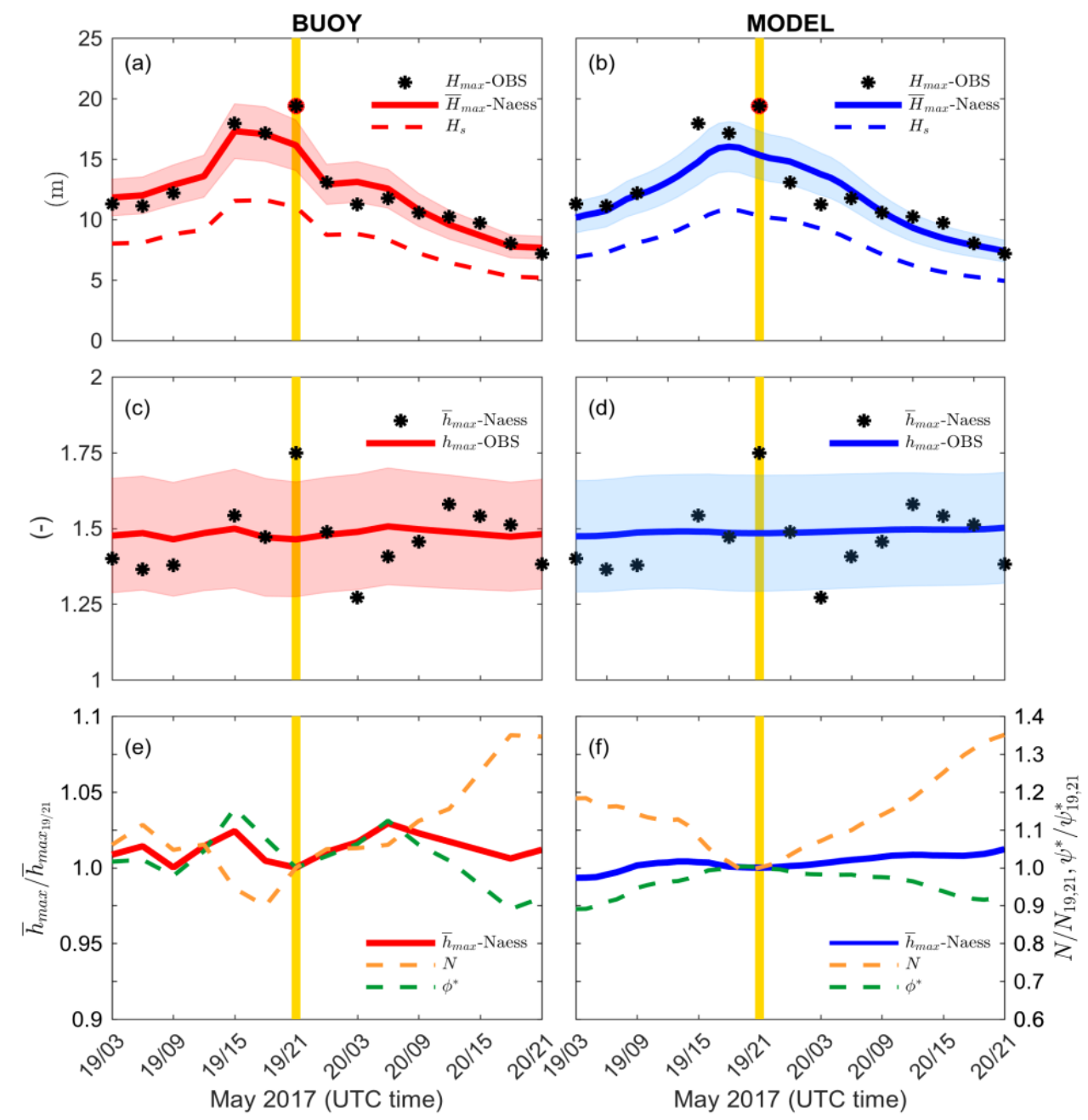

Figure 8 - (a,b) The evolution, over 19 and 20 May 2017, of $H_{s}$ and the maximum wave height $H_{\max }$ in each, observed and estimated, record according to the Naess model. Left panels buoy data, right ones model data. The coloured bands show the $72 \%$ confidence limits of the Naess estimates. The stars are the $H_{\max }$ actually measured in each record. (c,d) $H_{\max }$ values divided by the corresponding $H_{s}$. (e,f) As (c,d), but normalised with respect to the $19 / 21$ value. The first minimum $\psi$ of the autocovariance function and the average number of waves $\mathrm{N}$ are also shown, normalised with respect to the 19/21 values.

We now broaden our perspective passing from a single point to a $2 \mathrm{D}$ view of the situation. The single-point Naess approach does not consider the actual spatial distribution of waves in a storm. Its statistics would not change if the spectral components were coming, with an infinitely long crest, all from the same direction. Obviously this is not the case, especially with two wave systems (the present case) at one angle. The actual spatial distribution of $2 \mathrm{D}$ crests and troughs is essential for deciding which is the probability of a 
single point measurement, in our case the buoy, to pick up, e.g., a single particularly high wave or crest. A good quantitative estimate of this distribution is provided by the Space-Time Quasi-Determinism model (STQD, Benetazzo et al., 2017) combining the space-time extreme model of Fedele (2012) and Benetazzo et al. (2015) with the Quasi-Determinism theory of Boccotti (2000). This model has been verified with measurements at sea (stereo video) and proven to be accurate for the interpretation of high waves occurrence (Benetazzo et al., 2018; Benetazzo et al., 2017; Cavaleri et al., 2017). For this reasons it has been also implemented in the state-of-the-art WAVEWATCH III model (Barbariol et al., 2017; WW3DG, 2016) We provide here only the results of interest. The basic formulas and a very short description are given in Appendix A.

The large spatial variability in the cited cross-conditions implies that the single crests and waves have a relatively short life, both in space and time, before changing their characteristics, in particular their height. It follows that passing from the single point to a $2 \mathrm{D}$ view of the situation the probability of a large wave encounter increases dramatically. Indeed it turns out that the probability of encountering a $19.4 \mathrm{~m}$ high wave at $19 / 21$ jumps to $42 \%$ (i.e. \pm one standard deviation) if, instead of the single point, we consider a $60 \times 60 \mathrm{~m}^{2}$ area according to the buoy spectrum, and $44 \%$ and $70 \times 70 \mathrm{~m}^{2}$ according to the model. More on this on the final discussion of next section. Finally, the 2D view of the problem leads also to arguing about the expected shape of the large waves. A brief account of this is given in Appendix B.

\section{6 - Discussion and conclusions}

Whenever a large event is recorded, it is natural to ask how exceptional it was. For the case of the $19.4 \mathrm{~m}$ high wave south of New Zealand (see Figure 1), we approach the matter in two different ways.

The first one concerns the buoy. Buoys provide single point measurements. They are generally moored, which increases their natural tendency to avoid (turn around) the sharp crests. In so doing they tend to underestimate the crest and wave heights. Our unique dataset, including periods of both moored and drifting conditions, allows us to explore not only the related implications, but also to see how much measuring relative or absolute frequencies affects those results. In this last respect the data suggest that a free buoy tends to measure larger maximum wave heights, in our case by $2-3 \%$. The results appears robust enough and in the expected direction. We point out that a distinction should be done between the general 
current field, affecting the whole wave dynamics, and the Stokes drift that is more concentrated on the surface layer, hence with different effects on the dynamics of wave propagation. More could be said having at disposal the raw data. In this respect it is worthwhile to mention that a new buoy has been moored at the Campbell Island position. On 9 May 2018 this buoy measured (but with the discussed approximation) an almost $24 \mathrm{~m}$ high wave. We will have more to say when we dig more on the present and these new, also raw, data.

The second approach starts from the fact that the probability that particularly high waves pass exactly at the buoy position is relatively low. This is especially the case when we have cross-sea conditions because of the implied high spatial variability of the field. The 2D analysis shows that in the specific event a relatively small area, less than $0.3 L_{x} \times 0.3 L_{y}$ (respectively wave and crest length) for buoy spectrum and $0.55 L_{x} \times 0.4 L_{y}$ suffices for bringing the encounter probability to more than $40 \%$ within the $20 \mathrm{~min}$ record. This corresponds to $60 \times 60 \mathrm{~m}^{2}$ for the buoy data, $70 \times 70 \mathrm{~m}^{2}$ for the model ones. Probability reaches $100 \%$ if areas of $L_{x} L_{y}$ (buoy spectrum) and $1.5 L_{x} L_{y}$ (model spectrum) are considered. Indeed these low figures confirm the low spatial correlation of the field.

Both Naess and STQD are linear models for $H_{\max }$. The question is how much the non-linearity of the field can affect the above results. Casas-Prat \& Holthuijsen (2010) have shown that the buoy data (all moored buoys in their case) fit well a linear distribution. This is due also to the tendency of a buoy to cut off the higher crests, in so doing linearizing the field and the derived statistical distributions. Our data-set suggests this is especially the case for moored conditions, and the 2-3\% difference we have found for $H_{\max } / H_{s}$ statistics between moored and drifting conditions somehow confirms the general belief. This is also close to the estimate of the differences between non-linear and linear $H_{\max } / H_{s}$ statistics (3\% of the linear expected maximum, in our case), the highest non-linear crests being almost compensated by the upward lift of the troughs. The matter is completely different for the crests. However, given the loss of the buoy, in the present case the raw data are not available. Therefore we do not have data to argue on this aspect of the problem.

A different, highly non-linear explanation of freak waves is given by modulation instability. Dysthe et al. (2008), Onorato et al. (2001), (Janssen, 2003) have extensively worked on the field. Indeed Cavaleri et al. (2012) argue that the Louis-Majesty accident (which resulted in the death of people on a cruise ship) could be due to an instability arising 
from two similar wave converging systems, a situation somehow similar to the one we discuss here. However, in the present case there is no need to invoke highly non-linear processes as the present event, $19.4 \mathrm{~m}$ versus $\sim 11{\mathrm{~m} H_{S}}$, is far from the commonly accepted, 2 or 2.2, ratio for defining an event as freak.

We itemize our findings as follow:

1 - given the conditions of the storm, the $19.4 \mathrm{~m}$ wave was a particularly high, but not exceptional

2 - given the conditions, the probability of its appearing on the buoy record was about $7 \%$ (4\% using model spectrum) - however, in this respect we must not forget that we are focusing on the event a posteriori,

3 - given the large spatial and temporal variability of the field (following the two storm systems at an angle), the encounter probability jumps even to $100 \%$ if, instead of the singlepoint of a buoy, we consider an area from 1 to 1.5 times $L_{x} L_{y}$, with $L_{x}, L_{y}$ the wave and crest mean length respectively,

4 - there is a substantial indication of the tendency of a freely drifting buoy to measure slightly larger maximum wave heights, a moored buoy showing a higher tendency to move around the highest crests,

5 - the lack of the full raw data impedes any consideration on the effects of the non-linearity of the fields, something to be seen especially on the highest crests,

6 - a similar consideration holds for the effects of modulation instability potentially associated to dealing with two robust wave system approaching the area at an angle.

\section{Appendix A - The Space-Time Quasi Determinism model (STQD)}

Having reported in the text the main results, here we go a bit more in detail, providing the formulas and more extended results to be compared with the ones in Figure 8.

If a large crest height $C_{\max }$ or crest-to-trough height $H_{\max }$ is observed, most likely it occurred at the apex of a 3D wave group, i.e. at the point where the group reached its maximum vertical development. The space-time autocovariance function $\psi\left(x_{0}+x, y_{0}+\right.$ 
$y, t_{0}+t$ ), obtained from the directional wave spectrum (as its Fourier transform), provides the average space-time profile $\bar{\eta}\left(x_{0}+x, y_{0}+y, t_{0}+t\right)$ of the wave group close to the apex $\left(x_{0}, y_{0}, t_{0}\right)$, hence the one of the large wave. At the apex of the wave group development $(x=y=0, t=0)$, the expected maximum linear crest-to-trough wave height is estimated as (Benetazzo et al., 2017):

$$
\bar{H}_{\text {max }, S T Q D}=\left[C_{0}+\sigma \gamma\left(\xi_{0} \sigma^{-1}-\frac{2 N_{3} C_{0} \sigma^{-1}+N_{2}}{N_{3} C_{0}^{2} \sigma^{-2}+N_{2} C_{0} \sigma^{-1}+N_{1}}\right)^{-1}\right] \sqrt{2(1-\psi)}
$$

Here $C_{0} \sigma^{-1}$ is the mode of the distribution of space-time extreme elevations (namely, crests $C$ if the space-time domain considered is wide enough to observe the complete dynamics of wave groups), which is obtained as the largest positive solution of $\left(2 \pi N_{3 D} \frac{C_{0}{ }^{2}}{\sigma^{2}}+\sqrt{2 \pi} N_{2 D} \frac{C_{0}}{\sigma}+\right.$ $\left.N_{1}\right) \exp \left(\frac{-C_{0}{ }^{2}}{2 \sigma^{2}}\right)=1$, where $N_{3 D}, N_{2 D}$ and $N_{1 D}$ are the average number of waves within the space-time domain, on its faces and on its boundaries, respectively; $\psi=\psi\left(x_{0}, y_{0}, \mathrm{t}\right)$ is the first minimum of the time autocovariance function. The numbers of waves depend on the size of the space-time domain ( $X, Y$ over the 2D space; $D$ over time) and the size of the characteristic wave $\left(L_{x}, L_{y}, T_{m}\right)$, as well as some space-time and space-space correlation terms.

The first result of STQD is the size of the space domain ( $X Y$, the sea surface region) that is needed to observe a wave group whose highest wave has an expected wave height of 19.4-meter in a $D=1200 \mathrm{~s}$ sea state. The result (see the main text) is a very limited area, clearly showing, so to say, the limitations of the single-point measurements.

The different probability is better quantified repeating in Figure A1 the single point expected data in Figure 8, but for the spatial-temporal approach. Following the main text, the 19.4 m STDQ expected value has been estimated over a $60 \times 60 \mathrm{~m}^{2}$ for the measured spectra, and $70 \times 70 \mathrm{~m}^{2}$ for the model ones. Granted, because purposely built, the fit between the expectations and the $19.4 \mathrm{~m}$ wave, we see that, as expected from Figure 8, all the other measurements are lower. The interesting point is that the minimum of $\bar{h}_{\text {max,STQD }}=$ $\bar{H}_{\text {max STQD }} / H_{S}$ occurs right close to $19 / 21$. Hence, neither, for buoy and model, STQD seems to indicate favorable conditions for exceptional wave heights at this time. In contrast to what shown for the Naess predictions, more influenced by $\psi$ than by $N$, the normalized SQTD predictions are strongly modulated by the average number of waves $N_{w}$, which sums $N_{3 D}, N_{2 D}$ and $N_{1 D}$. Partially because of a larger spatial domain and partially because of smaller $L_{x}$ and $L_{y}$, the model-based $N_{w}$, also at $19 / 21$, is larger than the buoy-based one. Together with a 
larger $\psi$ at $19 / 21$, according to Eq. (2) this produces a larger $\bar{h}_{\text {max,STQD }}$, which compensates the smaller model $H_{s}$.
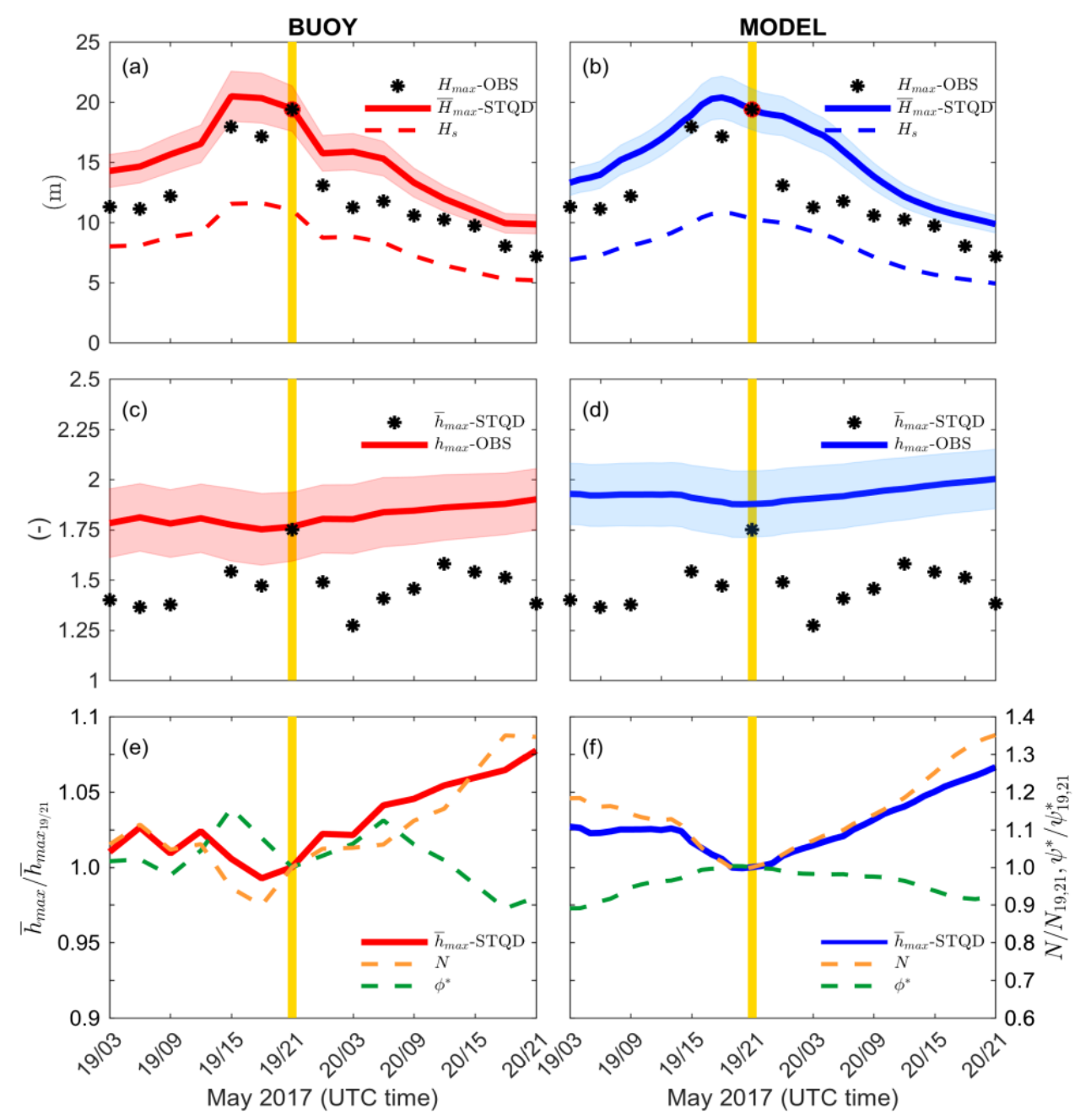

Figure A1 - (a,b) The evolution, over 19 and 20 May 2017, of the significant wave height $H_{S}$ and the estimated maximum wave height $H_{\max }$ in each record according to STQD model. Left panels buoy data, right ones model data. The coloured bands show the $72 \%$ confidence limits of the estimates. The stars are the $H_{\max }$ actually measured in each record. (c,d) $H_{\max }$ values divided by the corresponding $H_{s}$. (e,f) As (c,d), but normalised with respect to the $19 / 21$ value. The first minimum $\psi$ of the autocovariance function and the average number of waves $N_{w}=N_{3 D}+N_{2 D}+N_{1 D}$ are also shown, normalised with respect to the $19 / 21$ values.

\section{Appendix B - The shape of the large wave}

A further result of the STQD theory is the theoretical shape of the wave group and of the largest waves. 
In Figure B1 we show the expected time evolution of the highest single wave height (upper panel) and of the highest crest $C_{\max }$ (lower panel) on the base of the measured (solid, red) and model (dashed, blued) spectra. While, as intuitive, $C_{\max }$ happens at the peak of the group, this is not the case for $H_{\max }$. Indeed, given the shape of the group, the highest wave has an (almost) symmetric shape with respect to the centre of the group. Crest and trough are separated by $6.50 \mathrm{~s}$ for the measured, $6.25 \mathrm{~s}$ for the model spectrum.
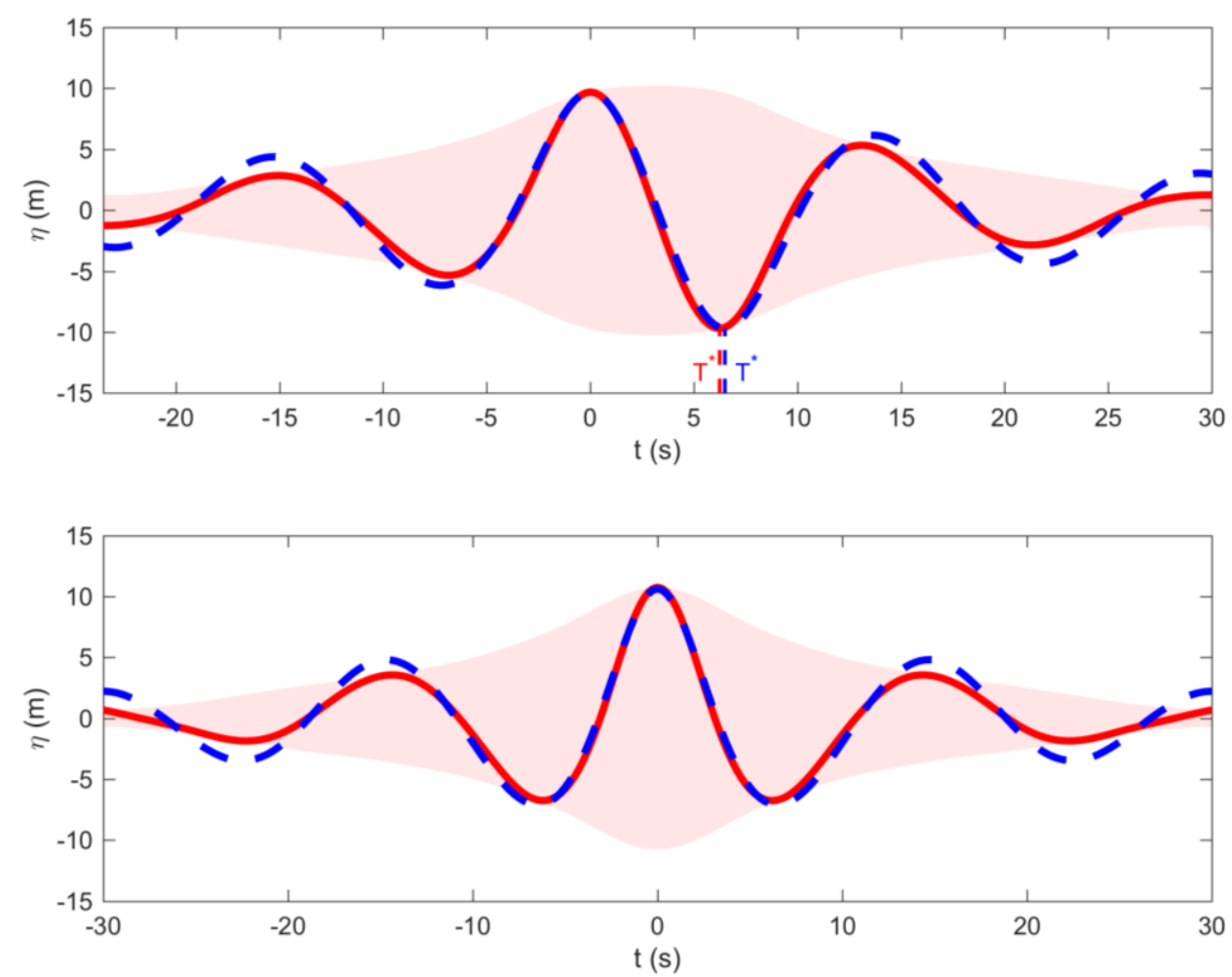

Figure B1 - (a) Time evolution of the wave with maximum height (19.4 m) from measured (red solid line) and model spectra (blue dashed line). (b) Time evolution of the maximum crest. The wave group envelope (only from the buoy spectrum) is represented by the shaded area.

It is worthwhile to remark the short spatial extent of the group. A common saying among mariners quotes one wave out of seven as the highest one in a group. This depends on the $2 \mathrm{D}$ spectrum and it holds for the single classical wind wave system. However, in crosssea conditions, as in our case, with two substantial wave systems coming across at an angle, the wave groups are much shorter, till the conditions in Figure B1 with only three waves. In this respect it is interesting to explore the spatial shape of the largest wave, again from the buoy (red) and model spectra (blue). Figure B2 provides the shape of the wave both in longitudinal (propagation) and transversal (along crest) directions. Following the nonsymmetric spectra with respect to their mean direction, also the wave shape is not symmetric. 
In relation to the cross-sea conditions, note in particular the short wave crest length and its expected non-symmetric shape.
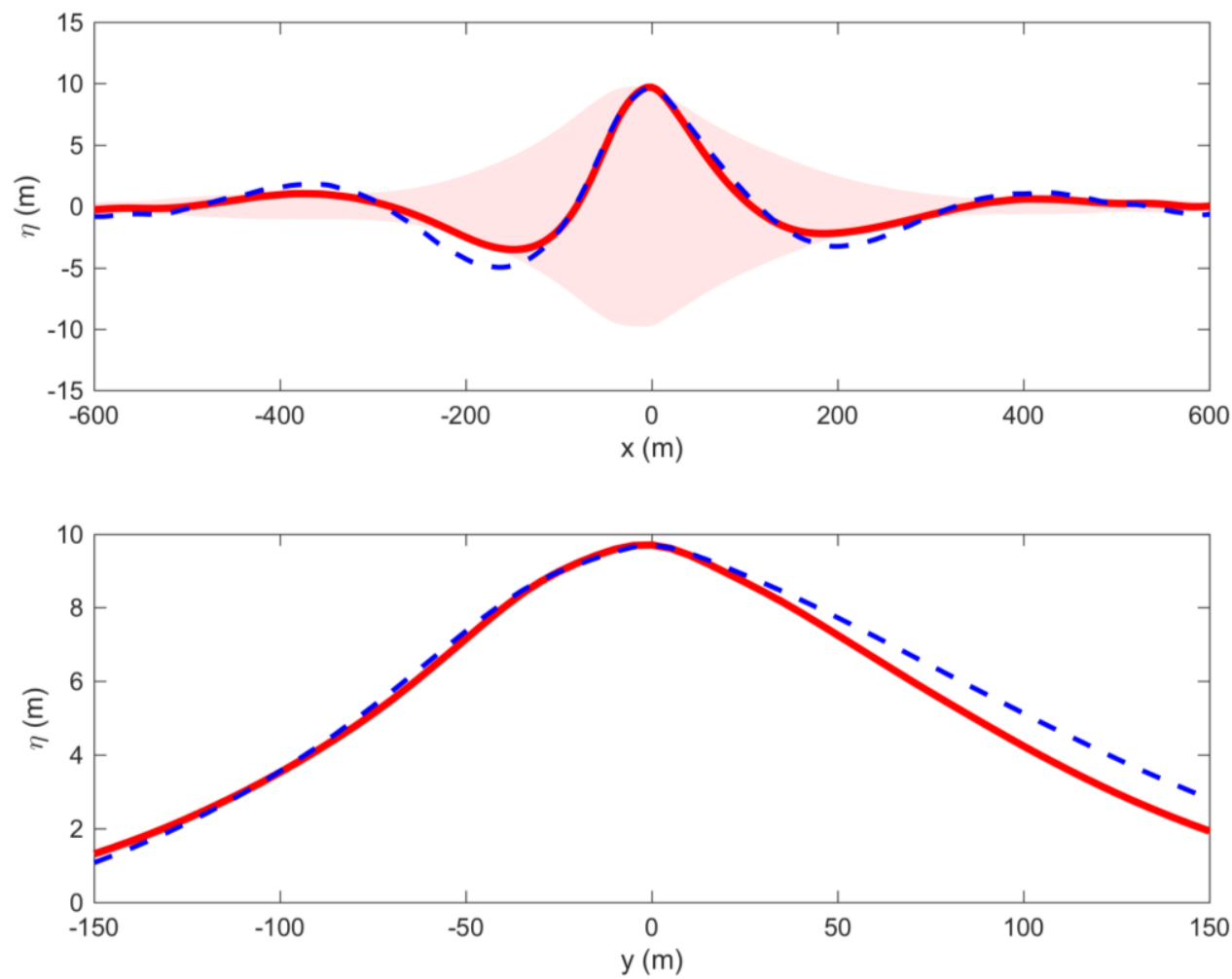

Figure B2 - (a) Longitudinal (propagation direction) shape of the wave with maximum height (19.4 m) from measured (solid, red) and model spectra (dashed, blue). The wave group envelope (only from the buoy spectrum) is represented by the shaded area. (b) As (a), but along the transversal (crest) direction.

\section{Acknowledgements}

Francesco Barbariol and Alvise Benetazzo have been supported by the Flagship Project "RITMARE" and by "Marine Strategy" (). Luciana Bertotti and Luigi Cavaleri have been partly supported by the EU contract 730030 call H2020-EO-2016 "CEASELESS". Tom Durrant is supported in part by the Office of Naval Research (contract N00014-17-S-B001 "Improved spectral characteristics in the Southern Ocean"). The buoy deployment itself was a collaboration between Metocean Solutions and The New Zealand Navy. 


\section{REFERENCES}

Alves, J. H. G. M. (2006). Numerical modeling of ocean swell contributions to the global wind-wave climate. Ocean Modelling, 11(1-2), 98-122. http://doi.org/10.1016/j.ocemod.2004.11.007

Barbariol, F., Alves, J.-H. G. M., Benetazzo, A., Bergamasco, F., Bertotti, L., Carniel, S., ... Tolman, H. (2017). Numerical modeling of space-time wave extremes using WAVEWATCH III. Ocean Dynamics, 67, 535-549. http://doi.org/10.1007/s10236-016-1025-0

Benetazzo, A., Ardhuin, F., Bergamasco, F., Cavaleri, L., Veras, P., Schwendeman, M., ... Torsello, A. (2017). On the shape and likelihood of oceanic rogue waves. Scientific Reports, 7(8276), 1-11. http://doi.org/10.1038/s41598-017-07704-9

Benetazzo, A., Barbariol, F., Bergamasco, F., \& Carniel, S. (2017). Space-time extreme wind waves : Analysis and prediction of shape and height. Ocean Modelling, 113, 201-216. http://doi.org/10.1016/j.ocemod.2017.03.010

Benetazzo, A., Barbariol, F., Bergamasco, F., Torsello, A., Carniel, S., \& Sclavo, M. (2015). Observation of extreme sea waves in a space-time ensemble. Journal of Physical Oceanography, 45(9), 2261-2275. http://doi.org/10.1175/JPO-D-15-0017.1

Benetazzo, A., Bergamasco, F., Yoo, J., Cavaleri, L., Sun-Sin, K., Bertotti, L., ... Jae-Seol, S. (2018). Characterizing the signature of a spatio-temporal wind wave field. Ocean Modelling, In press. http://doi.org/https://doi.org/10.1016/j.ocemod.2018.06.007

Boccotti, P. (2000). Wave Mechanics for Ocean Engineering. Elsevier Science B.V., 496 pp.

Casas-Prat, M., \& Holthuijsen, L. H. (2010). Short-term statistics of waves observed in deep water. Journal of Geophysical Research: Oceans (1978--2012), 115(C9).

Cavaleri, L., Benetazzo, A., Barbariol, F., Bidlot, J., \& Janssen, P. A. E. M. (2017). The Draupner event: the large wave and the emerging view. Bulletin of the American Meteorological Society, 98(4), 729-735.

Cavaleri, L., Bertotti, L., Torrisi, L., Bitner-Gregersen, E., Serio, M., \& Onorato, M. (2012). Rogue waves in crossing seas: The Louis Majesty accident. Journal of Geophysical Research: Oceans (1978--2012), 117(C11).

DNV GL - Det Norske Veritas Germanischer Lloyd. (2017). DNVGL-RP-C205: Environmental Conditions and Environmental Loads. DNV GL Recommended Practice, (August), 1-259. 
Draper, L. (1965). 'Freak' ocean waves. Mar. Obs., 35, 193-195. http://doi.org/10.1002/j.14778696.1966.tb05176.x

Dysthe, K., Krogstad, H. E., \& Müller, P. (2008). Oceanic rogue waves. Annu. Rev. Fluid Mech., 40, 287-310.

Fedele, F. (2012). Space--Time Extremes in Short-Crested Storm Seas. Journal of Physical Oceanography, 42(9), 1601-1615.

Fedele, F., \& Tayfun, M. A. (2009). On nonlinear wave groups and crest statistics. Journal of Fluid Mechanics, 620, 221-239.

Hemer, M. A. (2010). Historical trends in Southern Ocean storminess: Long-term variability of extreme wave heights at Cape Sorell, Tasmania. Geophysical Research Letters, 37(18), L18601. http://doi.org/10.1029/2010GL044595

Janssen, P. A. E. M. (2003). Nonlinear four-wave interactions and freak waves. Journal of Physical Oceanography, 33(4), 863-884.

Komen, G. J., Cavaleri, L., \& Donelan, M. (1994). Dynamics and Modelling of Ocean Waves. Cambridge University Press. Retrieved from https://books.google.it/books?id=7sg_PN_PDUkC

Longuet-Higgins, M. S., Cartwright, D. E., \& Smith, N. D. (1963). Observations of the directional spectrum of sea waves using the motions of a floating buoy. In Ocean Wave Spectra (pp. 111136). Prentice-Hall.

Naess, A. (1985). On the distribution of crest to trough wave heights. Ocean Engineering, 12(3), 221234. http://doi.org/10.1016/0029-8018(85)90014-9

Onorato, M., Osborne, A. R., Serio, M., \& Bertone, S. (2001). Freak waves in random oceanic sea states. Physical Review Letters, 86(25), 5831.

Rapizo, H., Babanin, A. V., Schulz, E., Hemer, M. A., \& Durrant, T. H. (2015). Observation of windwaves from a moored buoy in the Southern Ocean. Ocean Dynamics, 65(9-10), 1275-1288. http://doi.org/10.1007/s10236-015-0873-3

Rapizo, H., Durrant, T. H., \& Babanin, A. V. (2018). An assessment of the impact of surface currents on wave modeling in the Southern Ocean. Ocean Dynamics. http://doi.org/10.1007/s10236018-1171-7

Schulz, E. W., Josey, S. A., \& Verein, R. (2012). First air-sea flux mooring measurements in the 
Southern Ocean. Geophysical Research Letters, 39(16). http://doi.org/10.1029/2012GL052290

The WAVEWATCH III Development Group (WW3DG). (2016). User manual and system

documentation of WAVEWATCH III-version 5.16. College Park, MD, USA.

\section{Figure captions}

Figure 1 - Triaxis directional buoy mooring and drifting locations. The deployment was in the Southern Ocean at $52^{\circ} 45.71^{\prime} \mathrm{S}, 169^{\circ} 02.54^{\prime} \mathrm{E}$ (black cross), south-west of Campbell Island, south of New Zealand. The buoy was moored until July 27, 2017. Since then, it operated as a drifting buoy.

Figure 2 - Wind fields in the Southern Ocean at 03, 09, 15, 21, 03, 09 UTC 19-20 May 2017. Isotachs of $10-\mathrm{m}$ wind speed are at $4 \mathrm{~ms}^{-1}$ interval. The corresponding arrows are at 2-degree interval. The black dot shows the original position of the buoy when moored.

Figure 3 - Wave fields in the Southern Ocean at 03, 09, 15, 21, 03, 09 UTC 19-20 May 2017. Isolines of significant wave height are at $1 \mathrm{~m}$ interval. The corresponding arrows are at 2-degree interval. The black dot shows the original position of the buoy when moored.

Figure 4 - Time series of spectral wave parameters from the buoy (red) and the model (dashed, blue), during the storm that produced the highest wave height $(19.4 \mathrm{~m})$ recorded by the buoy. $H_{S}$ is spectral significant wave height, $T_{m}$ is mean spectral wave period, $\theta_{m}$ is mean wave direction, $\sigma_{s}$ is directional spreading, $\mu$ is an integral measure of mean wave steepness. The yellow line indicates the time the $19.4 \mathrm{~m}$ wave height occurred, with spectral parameter values at that time reported.

Figure 5 -Two-dimensional wave spectra from the Tryaxys buoy at 03, 09, 15, 21, 03, 09 19-20 May 2017. Energy density isolines at $20 \mathrm{~m}^{2} \mathrm{~s} \mathrm{rad}^{-1}$ interval.

Figure 6 - As Figure 5, but for model spectra.

Figure 7 - Evolution of the overall directional energy distribution $D(\vartheta)$ for the buoy and model spectra (upper and lower panels, respectively). The directional distributions are plotted at 6-hour interval. The 19/21 distribution is indicated by dashed black line.

Figure 8 - $(\mathrm{a}, \mathrm{b})$ The evolution, over 19 and 20 May 2017, of $H_{s}$ and the maximum wave height $H_{\max }$ in each, observed and estimated, record according to the Naess model. Left panels buoy data, right ones model data. The coloured bands show the $72 \%$ confidence limits of the Naess estimates. The stars are the $H_{\max }$ actually measured in each record. (c,d) $H_{\max }$ values divided by the corresponding 
$H_{s}$. (e,f) As (c,d), but normalised with respect to the $19 / 21$ value. The first minimum $\psi$ of the autocovariance function and the average number of waves $\mathrm{N}$ are also shown, normalised with respect to the $19 / 21$ values.

Figure A1 - (a,b) The evolution, over 19 and 20 May 2017, of the significant wave height $H_{S}$ and the estimated maximum wave height $H_{\max }$ in each record according to STQD model. Left panels buoy data, right ones model data. The coloured bands show the $72 \%$ confidence limits of the estimates. The stars are the $H_{\max }$ actually measured in each record. (c,d) $H_{\max }$ values divided by the corresponding $H_{S}$. (e,f) As (c,d), but normalised with respect to the $19 / 21$ value. The first minimum $\psi$ of the autocovariance function and the average number of waves $N_{w}=N_{3 D}+N_{2 D}+N_{1 D}$ are also shown, normalised with respect to the $19 / 21$ values.

Figure B1 - (a) Time evolution of the wave with maximum height $(19.4 \mathrm{~m})$ from measured (red solid line) and model spectra (blue dashed line). (b) Time evolution of the maximum crest. The wave group envelope (only from the buoy spectrum) is represented by the shaded area.

Figure B2 - (a) Longitudinal (propagation direction) shape of the wave with maximum height (19.4 m) from measured (solid, red) and model spectra (dashed, blue). The wave group envelope (only from the buoy spectrum) is represented by the shaded area. (b) As (a), but along the transversal (crest) direction.

\section{Table captions}

Table 1 - Mean value of the indicated parameters for moored and drifting conditions. $L_{m}$ is the mean wavelength (related to $T_{m}$ via the linear dispersion relationship). 